\title{
Recent Advances in the Colloidal Synthesis of Ternary Transition Metal Phosphides
}

https://doi.org/10.1515/zna-2019-0133

Received April 25, 2019; accepted May 22, 2019; previously

published online June 15, 2019

\begin{abstract}
Transition metal phosphides are interesting candidates for application as catalysts in electrochemical water splitting or heteroatom removal reactions, energy storage, and magnetic refrigeration. Metal phosphides can adopt a wide range of stoichiometries, and have metallic or semiconducting properties. The electronic and magnetic characteristics of metal phosphides can be further controlled by changing the size and the shape of the crystallites and by combining two different metals. In this review, the wet-chemical methods to synthesize such ternary $\mathrm{Fe}$, Co, and Ni phosphides are summarised. First, an overview of the general synthetic strategies and the crystallographic structure of the related materials is given. Then, examples of the synthesis of several ternary phosphides are described, and the motivation for synthesising the specific materials is discussed.
\end{abstract}

Keywords: Colloidal Synthesis; Ternary Phosphides; Transition Metals.

\section{Introduction}

Transition metal phosphides attract increasing scientific attention because of their catalytic, semiconducting, magnetocaloric, and magnetic properties [1-9]. In metal phosphides, phosphorus can adopt different oxidation states between 0 and -3 ; therefore, phosphides can be formed in a broad range of stoichiometries. Resulting compounds can range from metallic to semiconducting, depending on the ratio between the metal and phosphorus. Metal-rich phosphides (e.g. $\mathrm{M}_{3} \mathrm{P}$ or $\mathrm{M}_{2} \mathrm{P}$ ) show a similar electronic

\footnotetext{
*Corresponding author: Joanna Kolny-Olesiak, Energy and Semiconductor Research Laboratory, Department of Physics, Carl von Ossietzky University of Oldenburg, D-26111 Oldenburg, Germany, E-mail: joanna.kolny@uni-oldenburg.de
}

structure as pure metals and exhibit good electronic conductivity [10]. The electron delocalisation decreases with the increasing P-content and the ionic character of the M-P bonds increases; thus, most $\mathrm{MP}_{2}$ compounds are semiconductors. Also, the magnetic properties change with the composition, e.g. $\mathrm{Fe}_{3} \mathrm{P}$ and $\mathrm{Fe}_{2} \mathrm{P}$ are ferromagnetic and $\mathrm{FeP}$ is supermagnetic, while $\mathrm{FeP}_{2}$ and $\mathrm{FeP}_{4}$ are antiferromagnetic semiconductors [11]. This variety of different phases which can be formed with one metal, combined with size and shape control open up the possibility to fine-tune the properties of the resulting materials. However, it also complicates finding the optimum reaction condition for the synthesis of pure-phase nanocrystalline phosphides. Nevertheless, many examples of the syntheses of nanostructured binary phosphides can be found in the literature meanwhile, several review articles exist, giving a comprehensive overview of these results $[2-4,9,12-16]$.

The properties of metal phosphides can be influenced even further by combining two different metals. This possibility has been explored mainly to fine-tune the catalytic properties of transition metal phosphides in the oxygen and hydrogen evolution reaction (OER and HER, respectively). Transition metal phosphides have several characteristics, which make them suitable catalysts for electrochemical water splitting [17]. They exhibit sufficiently high electrical conductivity to ensure efficient charge transport during the catalytic reaction. Furthermore, they offer negatively charged phosphorus sites on the surface, which can trap protons. Nevertheless, the Gibbs free energy of the $\mathrm{H}$ adsorption is not too high, so that hydrogen can relatively easily leave the surface; especially when the P-rich compounds are stable in a wide range of $\mathrm{pH}$-values. That is why, such materials have the potential to replace rare and expensive noble metal catalysts, such as platinum or ruthenium.

Despite their interesting properties, still, not many examples of the synthesis of ternary transition metal phosphides have been published. In the following, general strategies applied in the synthesis of ternary phosphides are described, followed by some examples of wet-chemical methods for the generation of Fe-, Co-, and Ni-based ternary phosphides. 


\section{Synthesis of Ternary Transition Metal Phosphide}

\subsection{General Strategy}

A variety of P-sources have been explored in the synthesis of metal phosphides nanoparticles. Binary phosphides were synthesised using elemental, white phosphorus, which is highly reactive and allows for controlling the stoichiometry in a precise manner. Furthermore, reactions with white phosphorus can be conducted at a low temperature. $\mathrm{P}\left(\mathrm{SiMe}_{3}\right)_{3}$ and single source precursors are also highly reactive at low temperature. However, their availability is limited, and the reaction has to be conducted under air and water-free conditions. Alkyl and aryl phosphines, triphenyl phosphite, and aminophosphines are widely used P-sources, because of their comparatively secure handling and availability. However, they require a relatively high reaction temperature and have to be used in excess. Thus, the $\mathrm{M} / \mathrm{P}$ ratio cannot be controlled precisely in such reactions.

The most commonly used phosphorus source in the synthesis of ternary phosphide is trioctylphosphine (TOP), only a few reports use other alkyl or aryl phosphines. These compounds are also used to dissolve the metallic precursors and serve as ligands for the resulting particles. Also, oleylamine, hexadecylamine or oleic acid are used as stabilisers. Carbonyls and acetylacetonates are the most commonly used metal sources because they can be easily thermally decomposed or reduced, e.g. by oleylamine. The reactions take place in high boiling solvents, such as octadecene, oleylamine or benzyl ether. Although thermal decomposition of TOP can start at a relatively low temperature of $150{ }^{\circ} \mathrm{C}$ [18], it is promoted by the higher reaction temperature. Furthermore, the formation of crystalline metal phosphides usually requires relatively high temperature $\left(300-350^{\circ} \mathrm{C}\right)$. However, even at high temperature, the decomposition of TOP is not complete; thus, it has to be used in excess, and it is not possible to control precisely the ratio between the metals and phosphorus.

The synthesis of ternary compounds is usually more complicated, compared to the generation of binary ones [19], because it requires balancing the reactivity of two metallic compounds with different properties. Controlling their stoichiometry is crucial, as the composition of the resulting particles can strongly influence their catalytic or magnetic properties. However, the stoichiometry of phosphides obtained in the concurrent reaction of the a
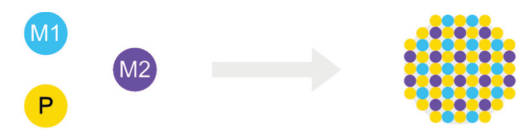

b
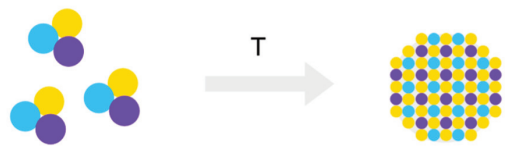

c $\mathrm{M}$
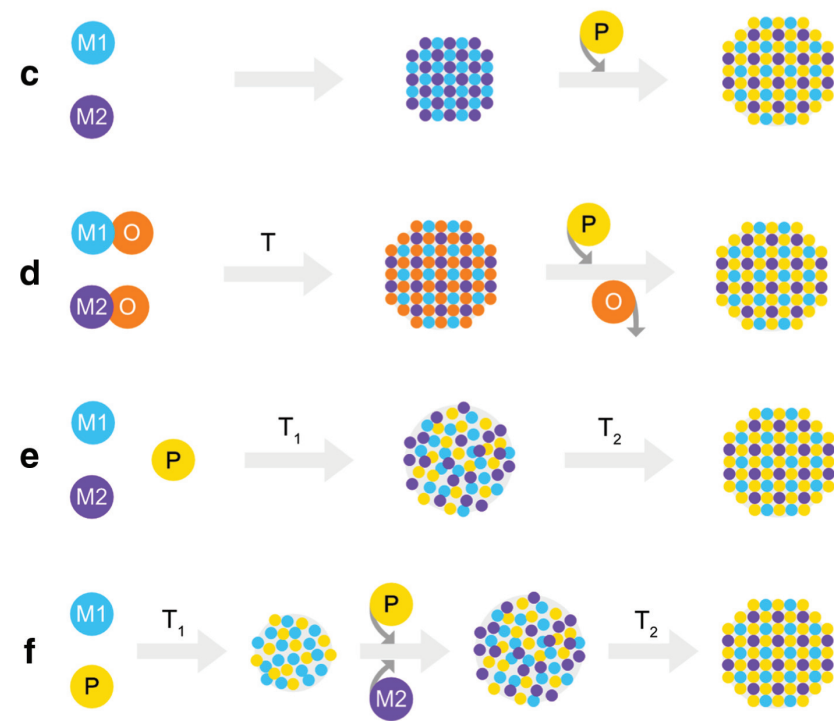

Figure 1: Reaction pathways leading to the formation of ternary phosphides. (a) Simultaneous reaction of both metal precursors (M1 and M2) with a phosphorus source (P). (b) Thermal decomposition of a single-source precursor containing both metals and phosphorus. (c) Formation of bimetallic particles and their subsequent phosphorisation. (d) Formation of oxidic particles and their subsequent phosphorisation. (e) Formation of amorphous M1-M2-P particles and their conversion to crystalline phosphides $\left(T_{2}>T_{1}\right)$. (f) Formation of amorphous M1-P particles, their reaction with $M 2$, and the conversion of the resulting amorphous M1-M2-P particles to crystalline phosphides $\left(T_{2}>T_{1}\right)$.

molecular metallic precursors with the phosphorus source (Fig. 1a) frequently does not reflect the ratio of the metals in the reaction solution [20-22]. Even using a singlesource precursor (Fig. 1b) might not be sufficient to control the final stoichiometry, because the presence of ligand molecules interacting more strongly with one of the metals can impair the control of the composition [23].

Therefore, some of the synthetic routes start with the formation of bimetallic (Fig. 1c) or oxidic (Fig. 1d) particles with the desired ratio between the two metals and convert them to phosphides subsequently. Also, multi-step syntheses starting with the formation of amorphous $\mathrm{M}-\mathrm{P}$ (or $\mathrm{M}-\mathrm{M}^{\prime}-\mathrm{P}$ ) precursor particles (Fig. 1e and f, respectively) turned out to be particularly suitable to control the composition of the final phosphides. In such syntheses, the 
ratio of both metallic precursors can influence the ratio of the two metals in the ternary phosphide, and several studies report the formation of ternary phosphides in the whole composition range between $\mathrm{M}_{2} \mathrm{P}$ and $\mathrm{M}_{2}^{\prime} \mathrm{P}$ [20, 21, 24-26].

Controlling the size of the resulting particles is essential, because of the size-dependent distribution of the metals among the possible different sites of the crystallographic structure, which can influence the catalytic properties of the resulting materials [27]. Generally, smaller particles form at higher TOP/metal ratio [28, 29]; however, by changing the TOP/metal ratio also the phase composition of the resulting samples can be altered. Thus, this strategy is not generally applicable. Also, the ratio between the two metals can influence the size of the particles [30,31], which renders independent control of the size and the composition of such particles difficult. Finally, organic compounds present in the reaction solution, which can influence the reactivity of the monomers and bind to the surface of the particles can be used to control the size and the shape of the particles [24].

Ternary phosphide particles with quasi-spherical $[24,32]$, nanorod $[22,30,31,33,34]$ or branched shapes
$[22,30,35]$ were reported in the literature. The formation of elongated particles is based on the anisotropy of the crystallographic structures, and the final morphology of the nanocrystals depends, not only on the presence of stabilisers but also can be influenced by the ratio between the two metals. Some of the compounds, especially cobaltrich particles, have a tendency to form voids [24, 28], based on the Kirkendall effect. Thus, the composition, size, and shape of ternary phosphide nanocrystals cannot be controlled entirely and independently.

\subsection{Crystallographic Structures}

Most of the ternary phosphides described in more detail in the next section can be derived from monometallic $\mathrm{M}_{2} \mathrm{P}$ and have the general $\left(\mathrm{M}_{\mathrm{x}} \mathrm{M}^{\prime}{ }_{1-\mathrm{x}}\right)_{2} \mathrm{P}$ stoichiometry. The relevant $\mathrm{M}_{2} \mathrm{P}$ compounds adopt three different crystallographic structures. $\mathrm{Fe}_{2} \mathrm{P}, \mathrm{Ni}_{2} \mathrm{P}$, and $\mathrm{Mn}_{2} \mathrm{P}$ crystallise in a hexagonal $\mathrm{Fe}_{2} \mathrm{P}$-type structure ( $\mathrm{P} \overline{\mathrm{C}} 2 \mathrm{~m}$ space group), while $\mathrm{Co}_{2} \mathrm{P}$ and $\mathrm{Ru}_{2} \mathrm{P}$ adopt the orthorhombic $\mathrm{Co}_{2} \mathrm{P}$ structure (Pnma space group). $\mathrm{P}$ atoms are located in the centre of trigonal prisms of metal atoms both in $\mathrm{Fe}_{2} \mathrm{P}$ and $\mathrm{Co}_{2} \mathrm{P}$.
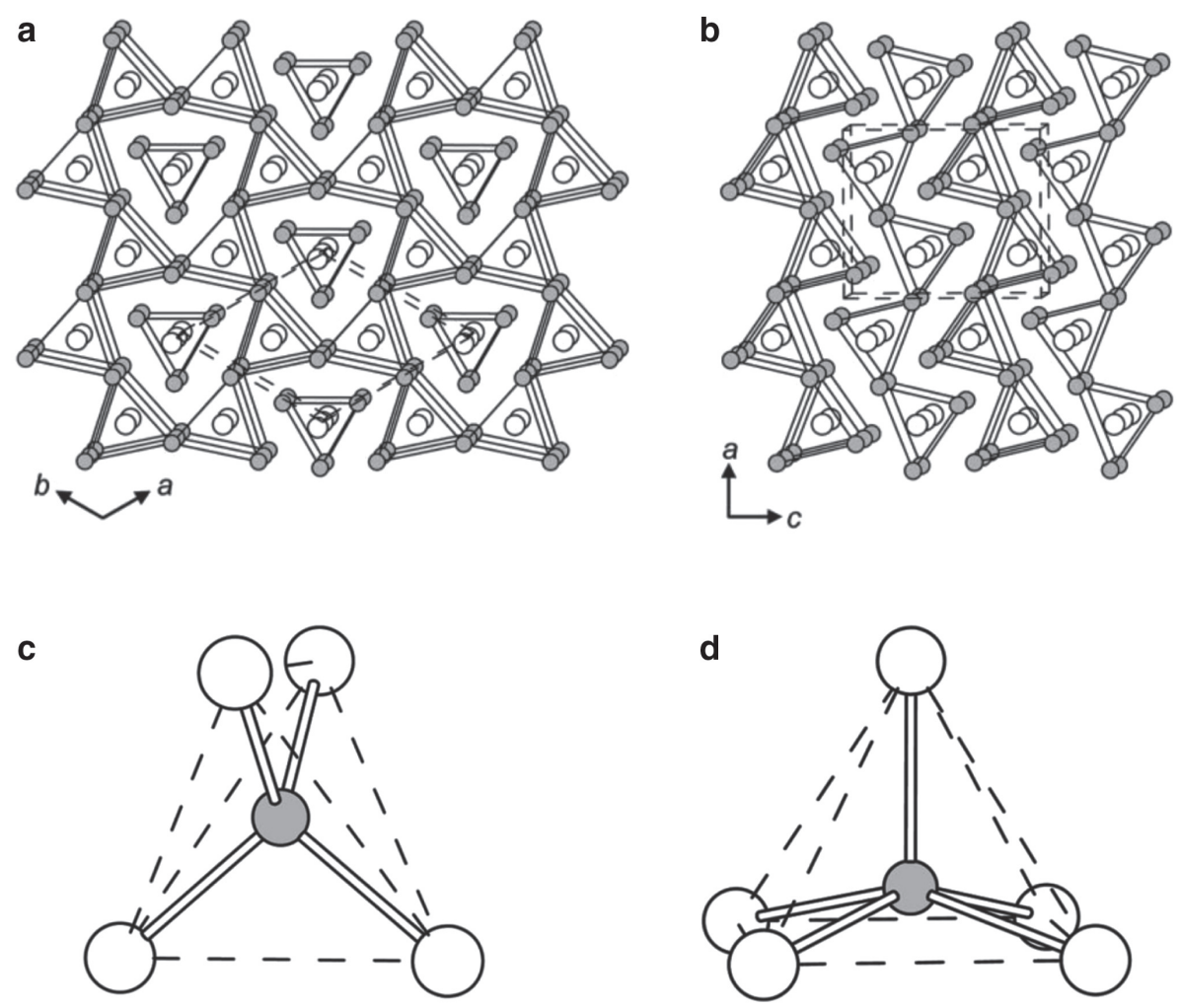

Figure 2: Structures of metal-rich phosphides $\mathrm{M}_{2} \mathrm{P}$ in terms of $\mathrm{P}$-centered $\mathrm{M} 6$ trigonal prisms; (a) $\mathrm{Fe}_{2} \mathrm{P}$ and (b) $\mathrm{CO}_{2} \mathrm{P}$. The small shaded circles are $M$ atoms and the large open circles are $P$ atoms. The trigonal prisms are oriented with their 3-fold axes perpendicular to the page. Coordination environments around $M$ atoms in $M_{2} P$ with (c) tetrahedral and (d) square pyramidal geometry. Adapted with permission from [10]. Copyright (2008) American Chemical Society. 
These prisms build a hexagonal framework in $\mathrm{Fe}_{2} \mathrm{P}$ and chains in $\mathrm{Co}_{2} \mathrm{P}$ (see Fig. 2a and b). Both structures have two different metal sites, one with tetrahedral (Fig. 2c) and the other with square pyramidal geometry (Fig. 2d), but the structures differ in the packing of both sites within the crystal. The tetrahedral site is smaller than the one with the square pyramidal geometry, thus it is likely that two different metals with different sizes (e.g. Fe: 125 pm, Ni: $121 \mathrm{pm}$ ) will not be distributed equally among these two different sites.

$\mathrm{Rh}_{2} \mathrm{P}$ crystallises in the antifluorite structure $(F m \overline{3} m$ space group), in which the metal occupies tetrahedral holes in an $f c c$ lattice formed by the phosphorus atoms.

\subsection{Examples of Ternary Phosphides}

\subsubsection{Co-Fe-P}

The interaction between cobalt and iron within one compound can influence the absorption energy of some of the catalytic species, which can reduce the over potential of the oxygen evolution reaction (OER) in alkaline media [27]. Furthermore, phosphorus-rich $\mathrm{Co}_{0.5} \mathrm{Fe}_{0.5} \mathrm{P}$ turned out to be an effective catalyst for the hydrogen evolution reaction (HER) [36]. Moreover, the magnetic properties of $\mathrm{Co}-\mathrm{Fe}-\mathrm{P}$ can be influenced by the incorporation of iron into the paramagnetic $\mathrm{Co}_{2} \mathrm{P}$; the resulting $\mathrm{Co}_{2-\mathrm{x}} \mathrm{Fe}_{\mathrm{x}} \mathrm{P}$ particles are ferromagnetic with a tunable Curie point close to room temperature [37]. Therefore, they are interesting candidates for applications, such as data storage, magnetic imaging or therapy.

Ye et al. [22] synthesised $\mathrm{Co}_{2-\mathrm{x}} \mathrm{Fe}_{\mathrm{x}} \mathrm{P}$ nanostructures in a reaction of metal oleates with trioctylphosphine in the presence of oleylamine. Depending on the reaction temperature, they obtained rice-shaped $\mathrm{Co}_{1.5} \mathrm{Fe}_{0.5} \mathrm{P}$ or split $\mathrm{Co}_{1.7} \mathrm{Fe}_{0.3} \mathrm{P}$ nanostructures (Fig. 3a and b). Both kinds of structures were demonstrated to be single crystalline (Fig. 3c). From the observation of the shape of the particles at different stages of the reaction, the authors could exclude aggregation as the formation mechanism of the split nanoparticles, which were formed at later stages of the reaction starting with the generation of nanodots and short nanorods. The formation of $\mathrm{Co}_{2} \mathrm{P}$-type ternary phosphides was only observed when an excess of iron(III) oleate was used. When a 1:1 ratio of both metals $(\mathrm{Co} / \mathrm{Fe})$ was applied, CoP-type particles were obtained. Despite using an iron excess in the reaction solution, only cobaltrich particles were obtained.

Lawes et al. [24] obtained $\mathrm{Co}_{\mathrm{x}} \mathrm{Fe}_{2-\mathrm{x}} \mathrm{P}$ in the whole composition range $(0 \leq \mathrm{x} \leq 2)$ in a single-pot, two-step synthesis. In the first step, $\mathrm{Co}_{\mathrm{x}} \mathrm{Fe}_{1-\mathrm{x}}$ alloy nanoparticles were obtained by decomposition of iron and cobalt carbonyl in octadecene in the presence of oleylamine at $200{ }^{\circ} \mathrm{C}$. Their subsequent reaction with TOP at temperatures between $330{ }^{\circ} \mathrm{C}$ and $350{ }^{\circ} \mathrm{C}$ yielded ternary phosphides with a hollow-sphere morphology (Fig. 3j-1), presumably, because of different diffusion rates of phosphorus and both metals. At intermediate values of $\mathrm{x}$, aggregation of small seed particles was identified as the growth mechanism of the particles, leading to the formation of particles with scalloped edges (Fig. 3k). While the cobalt-rich particles crystallised at a lower temperature, the formation of crystalline iron-richer particles required a reaction at a higher temperature. $\mathrm{Fe}_{2} \mathrm{P}$ and $\mathrm{Co}_{2} \mathrm{P}$ adopt two different structure types, hexagonal and orthorhombic, respectively (see Fig. 2a and b). Because of the small sizes of the crystallites and the consequent strong broadening of the reflections in the powder diffraction patterns of the particles with varying composition, the structure of the alloyed particles could not be assigned to one of both structure types. However, the shift of the positions of the reflections, compared to pure $\mathrm{Fe}_{2} \mathrm{P}$ or $\mathrm{Co}_{2} \mathrm{P}$, indicated the formation of a solid solution. The size of the particles was controlled by changing the amount of oleylamine, with larger particles forming at larger oleylamine concentration.

Another approach was used by Mendoza-Garcia et al. [30], who synthesised $\left(\mathrm{Co}_{\mathrm{x}} \mathrm{Fe}_{1-\mathrm{x}}\right)_{2} \mathrm{P}$ nanostructures by reacting presynthesized cobalt ferrite type $\left(\mathrm{CoFe}_{2} \mathrm{O}_{4}\right)$ $\mathrm{Co}-\mathrm{Fe}-\mathrm{O}$ nanoparticles with TOP. The ratio between the two metals could be adjusted by controlling the composition of the precursor nanoparticles, synthesised by thermal decomposition of iron(III) and cobalt(II) acetylacetonate in benzyl ether. Their morphology controlled the final shape of the phosphides; nanorods were formed from polyhedral oxide particles (Fig. 3d-f), while sea-urchin-like particles developed from cubic particles (Fig. 3g-i). The Co/Fe ratio controlled the dimensions of the nanorods and the arms of sea urchin-like particles, with thinner and longer structures forming at higher iron fractions. The formation of nanorods was possible up to an $\mathrm{x}$ value of 0.79 in $\left(\mathrm{Co}_{\mathrm{x}} \mathrm{Fe}_{1-\mathrm{x}}\right)_{2} \mathrm{P}$, above which hollow spherical nanoparticles were formed. Also, the center of the urchin-like particles turned out to be hollow, indicating a faster outward diffusion of oxygen then the inward diffusion of phosphorus. The nano-urchins did not form in the whole composition range but only at $0.24 \leq \mathrm{x} \leq 0.75$. Their generation was attributed to the strong passivation of (001) planes of the oxidic particles by oleic acid, favouring the growth of the phosphide along the $<110\rangle$ and $<111>$ direction. 


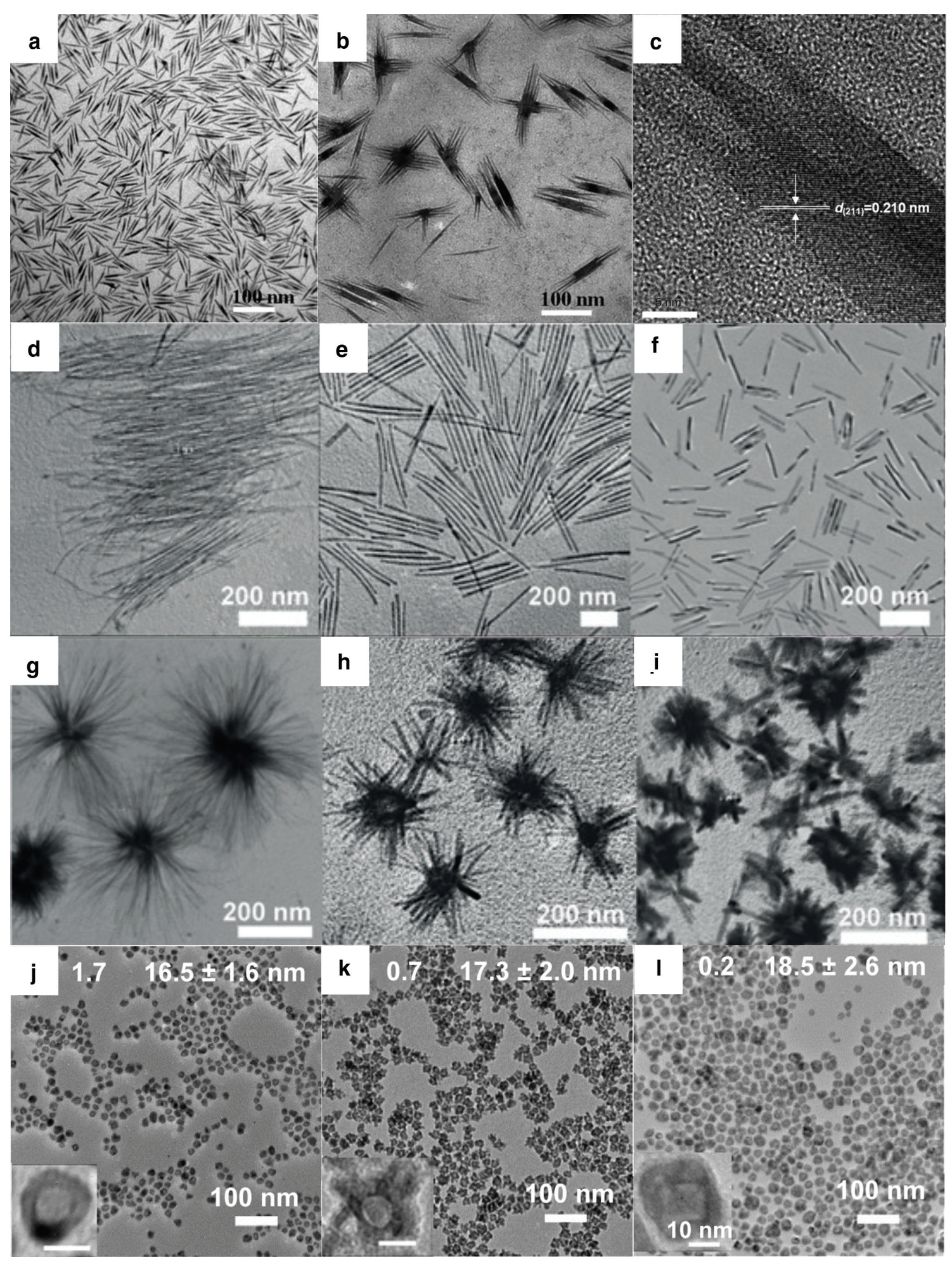

Figure 3: (a) TEM image of rice-shaped $\mathrm{C}_{1.5} \mathrm{Fe}_{0.5} \mathrm{P}$ nanorods prepared at $290{ }^{\circ} \mathrm{C}$ by the reaction of cobalt(II) oleate and iron (III) oleate

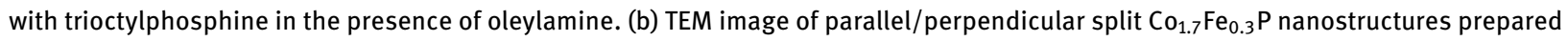
at $320^{\circ} \mathrm{C}$, (c) HRTEM investigation of single-crystalline split nanostructures prepared in the presence of oleylamine. Adapted with permission from [22]. Copyright (2011) John Wiley and Sons. (d)-(f) TEM images of the Co-Fe-P nanorods, showing the composition dependence of the length and thickness: (d) $\left(\mathrm{Co}_{0.16} \mathrm{Fe}_{0.84}\right)_{2} \mathrm{P}$, (e) $\left(\mathrm{Co}_{0.47} \mathrm{Fe}_{0.53}\right)_{2} \mathrm{P}$, and (f) $\left(\mathrm{Co}_{0.79} \mathrm{Fe}_{0.21}\right)_{2} \mathrm{P}$. (g) - (i) TEM images of the sea-urchin-like $\mathrm{Co}-\mathrm{Fe}-\mathrm{P}$, showing the composition-dependent dimension change of the nanourchin arms: (g) $\left(\mathrm{Co}_{0.24} \mathrm{Fe}_{0.76}\right)_{2} \mathrm{P}$, (h) $\left(\mathrm{Co}_{0.54} \mathrm{Fe}_{0.46}\right)_{2} \mathrm{P}$, and (i) $\left(\mathrm{Co}_{0.75} \mathrm{Fe}_{0.25}\right)_{2} \mathrm{P}$. Adapted with permission from [30]. Copyright (2015) John Wiley and Sons. (j)-(l) TEM images of hollow $\mathrm{Co}_{x} \mathrm{Fe}_{2-x} \mathrm{P}$ particles with different compositions; (j) $x=1.7,(k) x=0.7,(l) x=0.2$ (inset: HRTEM images, scale bars equal to $10 \mathrm{~nm}$ ). Adapted with permission from [24]. Copyright (2016) American Chemical Society. 


\subsection{2 $\mathrm{Ni}-\mathrm{Co}-\mathrm{P}$}

$\mathrm{Ni}_{2-\mathrm{x}} \mathrm{Co}_{\mathrm{x}} \mathrm{P}$ nanocrystals are attractive materials for catalytic applications, e.g. HER, OER, hydrodesulphurisation reactions or hydrazine decomposition, or can be applied as electrode material for supercapacitors and lithium-ion batteries [38, 39].

The first report about the formation of $\mathrm{Ni}-\mathrm{Co}-\mathrm{P}$ nanoparticles was published by Lu et al. [34], who synthesised $\mathrm{Co}_{1.33} \mathrm{Ni}_{0.67} \mathrm{P}$ nanorods via a slow injection of a mixture of nickel and cobalt acetylacetonate into oleylamine and TOP. The nanorods had an average length of $\sim 110 \mathrm{~nm}$ and width of $\sim 4.5 \mathrm{~nm}$ and grew along the $\mathrm{c}$ axis of the hexagonal unit cell.

A wider range of compositions was achieved by Liyanage et al. [28], who synthesised $\mathrm{Ni}_{2-\mathrm{x}} \mathrm{Co}_{\mathrm{x}} \mathrm{P}$ nanoparticles with $\mathrm{x} \leq 1.7$ in the size range of $9-14 \mathrm{~nm}$. They used a reaction between TOP and Ni and Co acetylacetonate complexes to generate $\mathrm{Ni}-\mathrm{Co}-\mathrm{P}$ alloy precursor particles, which were subsequently converted to crystalline ternary phosphide by prolonged heating the reaction solution to $350{ }^{\circ} \mathrm{C}$. As mentioned above, $\mathrm{Ni}_{2} \mathrm{P}$ and $\mathrm{Co}_{2} \mathrm{P}$ have a hexagonal and an orthorhombic crystallographic structure, respectively. The particles exhibit the hexagonal $\mathrm{Ni}_{2} \mathrm{P}$ structure up to the $\mathrm{Ni}_{0.67} \mathrm{Co}_{1.33} \mathrm{P}$ stoichiometry, while Rietveld refinement of cobalt-richer samples shows a better agreement with the orthorhombic $\mathrm{Co}_{2} \mathrm{P}$ structure (left side of Fig. 4). The particles are quasi-spherical and have a narrow size distribution (right side of Fig. 4). However, at larger cobalt concentrations their size distribution broadens, and the formation of voids can be observed within the particles, in analogy to pure $\mathrm{Co}_{2} \mathrm{P}$ nanostructures [40, 41].

Branched $\mathrm{Ni}_{2-\mathrm{x}} \mathrm{Co}_{\mathrm{x}} \mathrm{P}$ nanoparticles were synthesised by Marusak et al. [35] in a reaction of presynthesised $\mathrm{Ni}_{\mathrm{x}} \mathrm{Co}_{\mathrm{y}}$ nanocrystals with $\mathrm{TOP}$, or a reaction of Ni nanoparticles with TOP in the presence of cobalt acetylacetonate
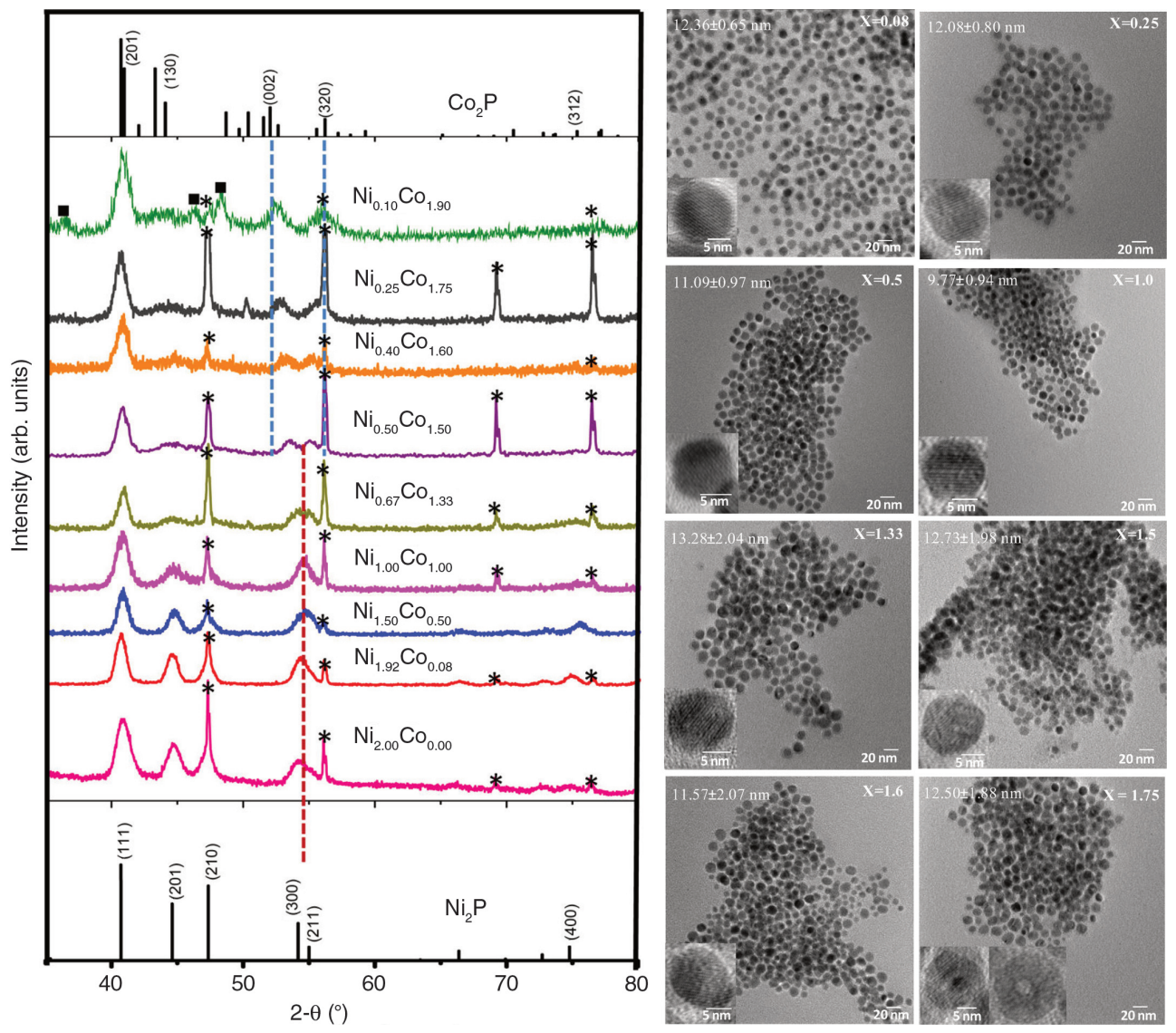

Figure 4: PXRD patterns for different targeted compositions of $\mathrm{Ni}_{2-} \mathrm{Co}_{x} \mathrm{P}$. Reference patterns for $\mathrm{Co}_{2} \mathrm{P}$ and $\mathrm{Ni}_{2} \mathrm{P}$ are shown for comparison with drop lines indicating the major distinguishing peaks for the two phases. The sharp peaks denoted with * arise from an internal $\mathrm{Si}$ standard. Peaks denoted with $\mathbf{\square}$ arise from a CoP impurity. TEM images for $\mathrm{Ni}_{2-x} \mathrm{Co}_{x} \mathrm{P}$ nanoparticles (targeted compositions indicated). The insets illustrate HRTEM images for each composition showing lattice fringes and, for $x=1.75$, hollow particle formation. Adapted with permission from [28]. Copyright (2015) American Chemical Society. 


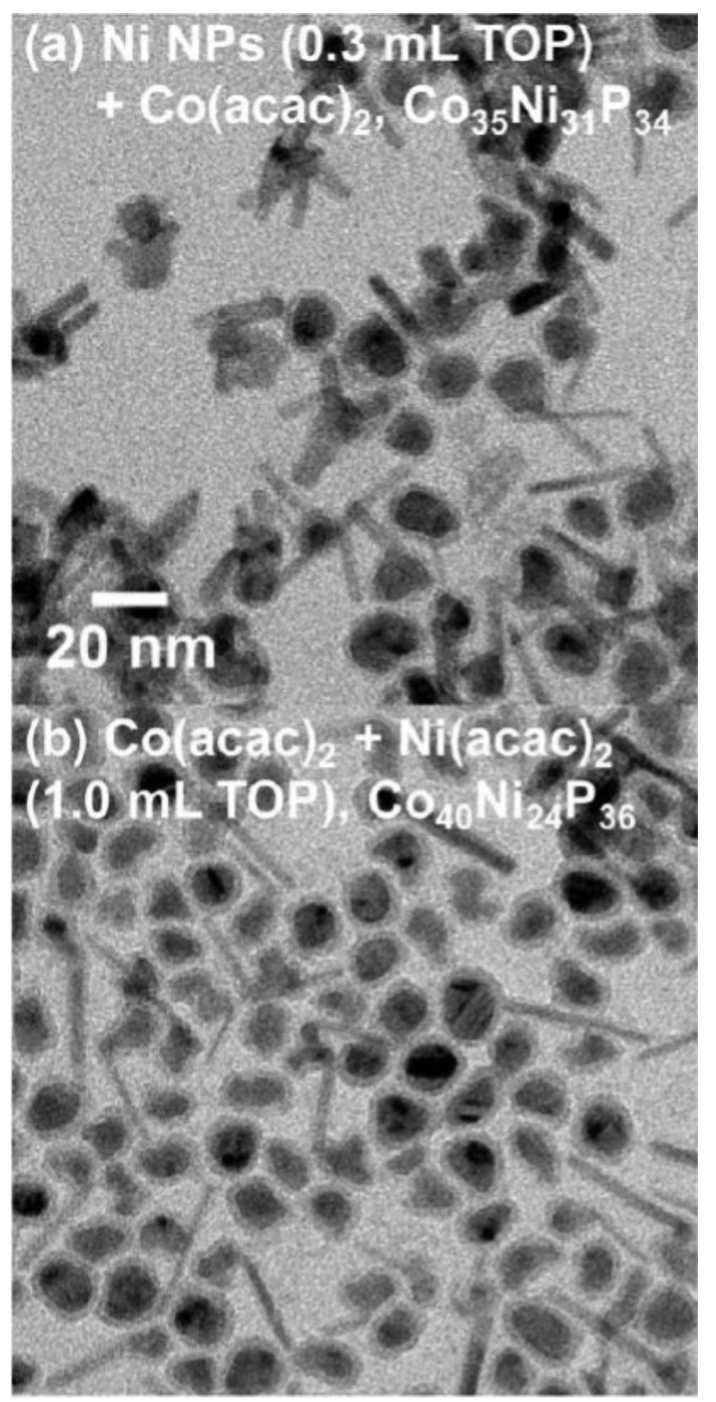

Figure 5: TEM images (common scale bar) of $\mathrm{CO}_{2-x} \mathrm{Ni}_{x} \mathrm{P}$ NPs synthesised using (a) Ni(acac $)_{2}$ with TOP heated to $240{ }^{\circ} \mathrm{C}$, followed by addition of $\mathrm{Co}(\mathrm{acac})_{2}$ and heating to $300{ }^{\circ} \mathrm{C}$. (b) $\mathrm{Ni}(\mathrm{acac})_{2}$, $\mathrm{Co}(\mathrm{acac})_{2}$, and TOP heated to $300^{\circ} \mathrm{C}$. Adapted with permission from [35]. Copyright (2017) American Chemical Society.

(Fig. 5a and b). The resulting particles had a hexagonal crystallographic structure, and their branches were cobalt-rich.

Liang et al. [25] synthesised $\mathrm{Ni}_{2-\mathrm{x}} \mathrm{Co}_{\mathrm{x}} \mathrm{P}$ nanoparticles in the whole composition range $(0 \leq \mathrm{x} \leq 2)$ by a reaction of nickel and cobalt acetate with triphenylphosphine in the presence of $\mathrm{NaBH}_{4}$, which facilitated the formation of the ternary phosphide at a lower reaction temperature and shorter reaction time $\left(2 \mathrm{~h}\right.$ at $250{ }^{\circ} \mathrm{C}$ vs. $6 \mathrm{~h}$ at $330{ }^{\circ} \mathrm{C}$ without $\mathrm{NaBH}_{4}$ ). The particles were in a size range between 3 and $11 \mathrm{~nm}$ and adopted the crystallographic structure of $\mathrm{Ni}_{2} \mathrm{P}$ for nickel-rich compositions, while a transition to the $\mathrm{Co}_{2} \mathrm{P}$ structure was observed, starting with the NiCoP stoichiometry.
A reaction of metal chlorides with triphenyl phosphite (TPP) in the presence of hexadecylamine (HDA) was used by Liu et al. [31] to synthesise $\mathrm{Ni}_{2-\mathrm{x}} \mathrm{Co}_{\mathrm{x}} \mathrm{P}$ nanoparticles with $0 \leq \mathrm{x} \leq 2$. For $\mathrm{x} \leq 1$, quasi-spherical particles were obtained, while elongated structures and nanorods were formed for $x \geq 1.2$ (Fig. 6). HDA had a substantial impact on the shape of the resulting particles, especially for Co-rich compositions, because of the stronger interaction of HDA with cobalt than with nickel. This synthesis using simple and low-cost precursors turned out to be well-reproducible and could be up-scaled to produce nanoparticles at the gram scale.

The composition of the surface-near regions of $\mathrm{Ni}_{2-\mathrm{x}} \mathrm{Co}_{\mathrm{X}} \mathrm{P}$ particles was studied by $\mathrm{x}$-ray photoelectron spectroscopy (XPS) $[25,28,31]$, revealing the presence of an oxidised layer containing all three elements. Furthermore, the surface was phosphorus-rich, indicating loss of metal ions during the washing procedure or the presence of a phosphorus-containing ligand shell. The surface near regions were also Co-rich, which might be due to cobalt's slightly higher affinity to oxygen, compared to nickel.

\subsubsection{Fe-Ni-P}

Incorporating iron into $\mathrm{Ni}_{2} \mathrm{P}$ can improve its catalytic properties, as was demonstrated, e.g. for the hydrodesulfurization reaction of thiophene [42]. On the other hand, the presence of a small fraction of nickel in $\mathrm{Fe}_{2} \mathrm{P}$ can increase the Curie temperature of this compound to values near room temperature, which is essential for applications, such as, magnetic refrigeration [43]. Thus, Ni-Fe-P compounds exhibit interesting properties, which could be modified and improved by producing $\mathrm{Ni}-\mathrm{Fe}-\mathrm{P}$ nanostructures with different sizes, shapes, and compositions.

Yoon et al. [33] synthesized $\left(\mathrm{Fe}_{\mathrm{x}} \mathrm{Ni}_{1-\mathrm{x}}\right)_{2} \mathrm{P}$ nanorods with a hexagonal $\mathrm{Fe}_{2} \mathrm{P}$ structure, growing along the $<001>$ direction, by a reaction of $\mathrm{Fe}(\mathrm{CO})_{5}$ and nickel acetylacetonate with TOP. The preformed Ni-TOP complex was continuously injected into the reaction solution by a syringe pump. By changing the rate of the injection, the composition and the length of the resulting nanorods could be controlled, and the authors demonstrated the formation of nanorods with three different stoichiometries $\left(\mathrm{Fe}_{1.8} \mathrm{Ni}_{0.2} \mathrm{P}\right.$, $\mathrm{Fe}_{1.6} \mathrm{Ni}_{0.4} \mathrm{P}$, and $\mathrm{Fe}_{1.5} \mathrm{Ni}_{0.5} \mathrm{P}$ ). The formation of nanorods was explained by the anisotropy of the hexagonal $\mathrm{Fe}_{2} \mathrm{P}$ structure and the preferential binding of the TOP ligands to surfaces perpendicular to the $<002>$ direction. That is why the relative amount of TOP had an influence on the aspect ratio of the resulting particles: at 

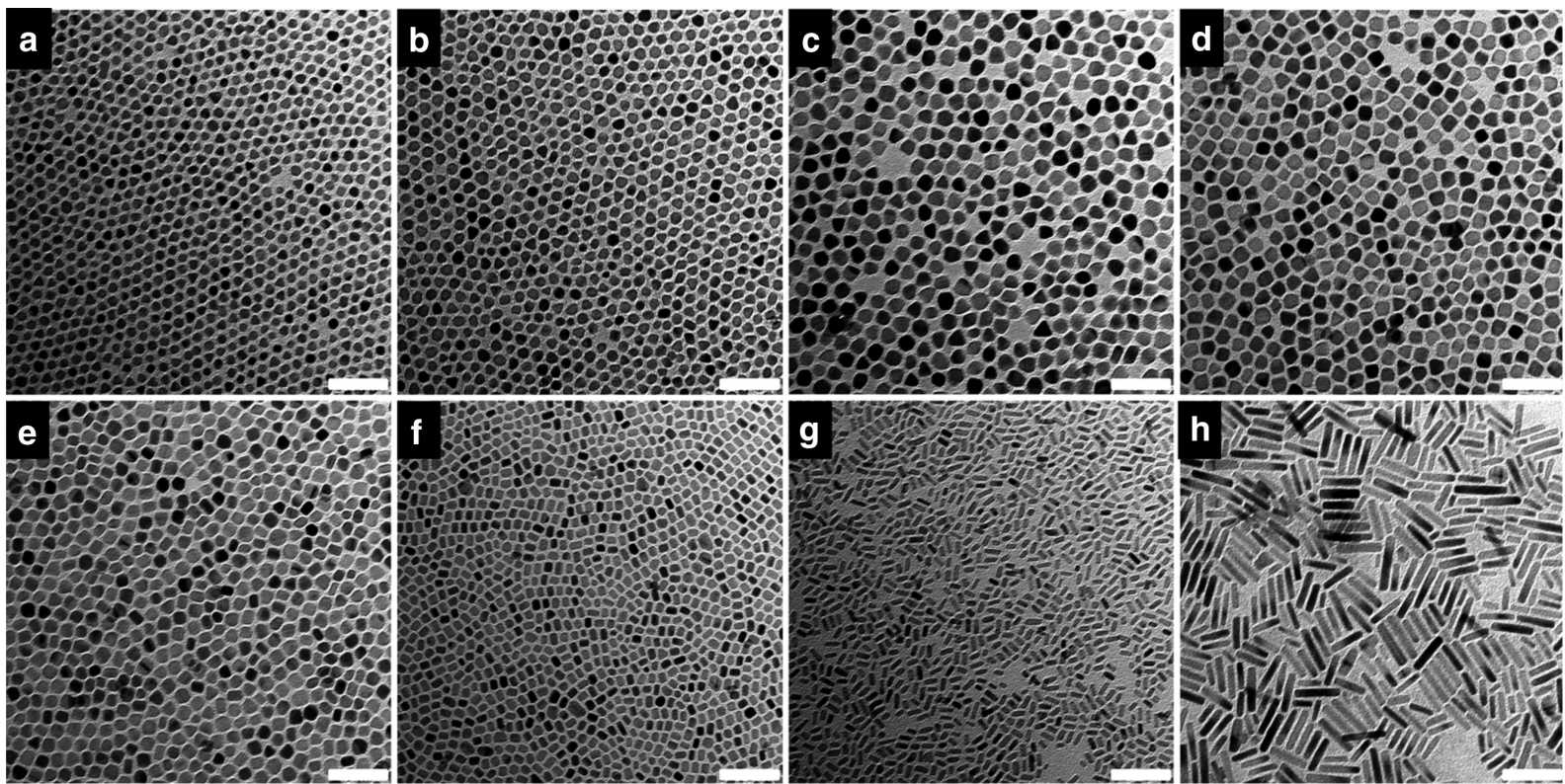

Figure 6: TEM images of $\mathrm{Ni}_{2-\mathrm{x}} \mathrm{Co}_{x} \mathrm{P}$ NCs with different compositions: $\mathrm{x}=0$ (a), $0.2(\mathrm{~b}), 0.6$ (c), 1 (d), $1.2(\mathrm{e}), 1.4(\mathrm{f}), 1.8$ (g), and 2 (h). Scale bars $=50 \mathrm{~nm}$. Reprinted with permission from [31]. Copyright (2018) Royal Society of Chemistry.

low TOP concentrations, quasi-spherical particles were formed, while the length of the nanorods increased and their thickness decreased when more TOP was used. The nanorods showed a strong tendency to form superstructures with a hexagonal arrangement of the individual nanorods.

Hitihami-Mudiyanselage et al. [26] obtained $\mathrm{Fe}_{\mathrm{X}} \mathrm{Ni}_{2-\mathrm{x}} \mathrm{P}$ particles in the whole composition range $(0 \leq \mathrm{x} \leq 2)$ in a one-pot, three-step method, using nickel acetylacetonate and $\mathrm{Fe}(\mathrm{CO})_{5}$ as the sources of the metals and TOP as the phosphorus source. Because of the lower reactivity of the nickel precursor, amorphous Ni-P particles were generated first, before introducing the iron source into the reaction solution. In the presence of iron, amorphous $\mathrm{Ni}-\mathrm{Fe}-\mathrm{P}$ particles were obtained, which could subsequently be converted into crystalline $\mathrm{Fe}_{\mathrm{x}} \mathrm{Ni}_{2-\mathrm{x}} \mathrm{P}$ particles by heating the reaction solution to $350{ }^{\circ} \mathrm{C}$. The resulting particles crystallise in the hexagonal $\mathrm{Fe}_{2} \mathrm{P}$ structure-type, and the lattice parameters change with the composition. However, there is no linear dependence of the composition and the change of the lattice parameters. This was attributed to the presence of two different sites for the metal atoms in the $\mathrm{Fe}_{2} \mathrm{P}$ structure (see Fig. $2 \mathrm{c}$ and d), which are not populated equally by the two metals. Iron, which is slightly larger than nickel, preferentially occupies the larger, square pyramidal site at higher iron concentration. Mössbauer spectroscopy measurements confirmed this tendency. The morphology of the particles was dependent on their composition; nickel-rich particles were quasi-spherical, and at higher iron fractions elongated particles were formed (Fig. 7).

\subsubsection{Co-Mn-P}

Manganese-based phosphides are interesting candidates for water oxidation catalysts; however, this class of materials has not been studied in detail, yet. While MnP is not stable under oxidising conditions, the activity of manganese can be lowered by combing it with another metal, e.g. cobalt. That is why Li et al. [44] synthesised orthorhombic CoMnP nanocrystals and demonstrated their capability to catalyse water oxidation. The particles were obtained by a reaction of $\mathrm{Co}_{2}(\mathrm{CO})_{8}$ and $\mathrm{Mn}_{2}(\mathrm{CO})_{10}$ with TOP in oleylamine and octadecene. Interestingly, pure $\mathrm{Mn}_{2} \mathrm{P}$ could not be synthesised, indicating that the presence of Co facilitates the inclusion of lowvalent $\mathrm{Mn}$ into the ternary phosphide.

\subsubsection{Fe-Mn-P}

Colson and Whitmire [23] synthesised $\mathrm{Fe}_{2-\mathrm{x}} \mathrm{Mn}_{\mathrm{x}} \mathrm{P}$ nanocrystals by a decomposition of a single source precursor, $\mathrm{FeMn}(\mathrm{CO})_{8}\left(\mu-\mathrm{PH}_{2}\right)$ in dioctylether in the presence of oleic acid and hexadecylamine. Despite using a precursor with a 1:1 ratio between the two metals, iron-rich compositions were obtained. Oleic acid was identified as an agent promoting the growth of the nanoparticles and 

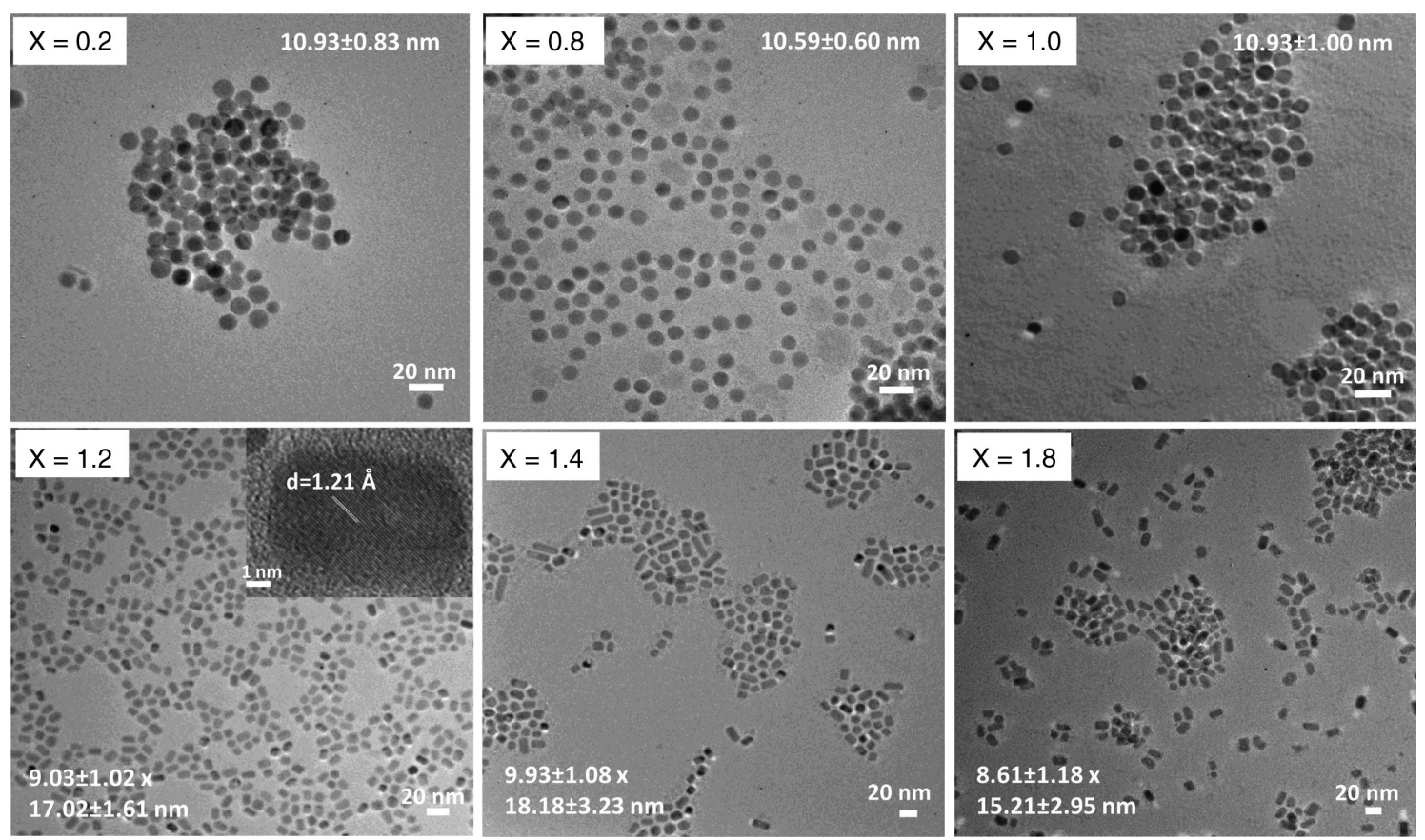

Figure 7: TEM micrographs of $\mathrm{Fe}_{x} \mathrm{Ni}_{2-x} \mathrm{P}$ nanoparticles. For $\mathrm{x}=1.2,1.4$, and 1.8 aspect ratios are 1.88, 1.83, and 1.77, respectively. The inset for $x=1.2$ shows a high-resolution image with lattice fringes corresponding to the (302) reflection. Adapted with permission from [26].

Copyright (2015) American Chemical Society.

also leading to the leaching of manganese atoms, which have a higher affinity to this ligand molecule, compared to iron.

\subsubsection{Co-Rh-P}

Incorporation of rhodium into cobalt phosphide can improve its electrocatalytic activity towards the oxygen evolution reaction. However, the phase diagram of cobalt rhodium phosphide has not been studied, yet, and the only known composition of a ternary phosphide in this system is CoRhP [45, 46].

Cobalt rhodium phosphides were synthesised by a co-reduction of both metal ions followed by phosphidation of the bimetallic intermediate compound by Mutinda et al. [21]. While Co-rich particles adopt the structure of orthorhombic $\mathrm{Co}_{2} \mathrm{P}$, Rh-rich nanocrystals exhibited the cubic antifluorite $\mathrm{Rh}_{2} \mathrm{P}$ structure. Despite the differences between the crystallographic structures of both monometallic phosphides, cobalt rhodium phosphides were obtained in a wide range of compositions. The transition between the two different crystallographic structures occurred about the 1:1:1 composition. The authors identified the addition of TOP, acting as the source of phosphorus, after the formation of the bimetallic intermediate compound as crucial to the composition control of the ternary phosphides. The presence of TOP at earlier stages of the reaction leads to the formation of cobalt-rich compounds. Although rhodium is a noble metal, which should be reduced easily under the reaction conditions in this study, the activity of the rhodium precursor was substantially lower in the presence of TOP. Also, the choice of temperature was essential to ensure the phase purity of the product. At higher temperature CoP was formed instead of $\mathrm{Co}_{2} \mathrm{P}$.

\subsubsection{Ni-Ru-P}

Ruthenium-based materials are promising catalysts for OER. However, $\mathrm{Ru}$ is a scarce and expensive element. This motivates research activities towards developing catalysts which combine Ru with other, earth-abundant, elements, e.g. a combination of ruthenium and nickel in the form of a bimetallic phosphide. Liyanage et al. [20] studied the colloidal synthesis of this material and obtained $\mathrm{Ni}-\mathrm{Ru}-\mathrm{P}$ particles by a reaction of ruthenium particles generated from ruthenium chloride with nickel acetylacetonate, and finally with TOP. Similarly to the synthesis of Co-Rh-P particles described above, the absence of TOP during the formation of the ruthenium particles and their further reaction with the Ni-source was essential for the successful formation of the ternary phosphide particles. The resulting particles $\left(\mathrm{Ni}_{2-\mathrm{x}} \mathrm{Ru}_{\mathrm{x}} \mathrm{P}\right.$ with $\left.\mathrm{x} \leq 1\right)$ crystallised in the $\mathrm{Fe}_{2} \mathrm{P}$-type hexagonal $\mathrm{Ni}_{2} \mathrm{P}$ structure. 
Although NiRuP crystallises in the orthorhombic $\mathrm{Ru}_{2} \mathrm{P}$ structure in the bulk, the nanocrystals with this composition also adopted the $\mathrm{Ni}_{2} \mathrm{P}$ structure. The sizes of the crystallites and their tendency to aggregation decreased with increasing ruthenium content and their shape changed from quasi-spherical to elongated. Particles with Ru-rich composition $\left(\mathrm{Ni}_{2-\mathrm{x}} \mathrm{Ru}_{\mathrm{x}} \mathrm{P}\right.$ with $\left.\mathrm{x}>1\right)$ showed worm-like morphology and were amorphous, probably due to a too low reaction temperature, limited by the used solvent.

\section{Conclusions}

Ternary phosphides show promising properties, especially as catalysts in electrochemical water splitting. They also exhibit interesting magnetic properties. However, this class of materials has not been studied in detail, yet. Only a few nanoscale ternary compounds have been synthesised and characterised, the majority of them are metallic phosphides with the $\left(\mathrm{M}_{\mathrm{x}} \mathrm{M}_{1-\mathrm{x}}^{\prime}\right)_{2} \mathrm{P}$ stoichiometry. P-richer, semiconducting ternary phosphides have not been studied, yet, despite their potential to be effective photocatalysts, or the possibility to show improved efficiency as HER catalyst, because of the presence of phosphorus sites with a larger negative charge. The synthesis of P-richer compounds with a stronger covalent component in the $\mathrm{M}-\mathrm{P}$ and $\mathrm{P}-\mathrm{P}$ bonds generally requires a longer reaction time or higher temperature. The latter is not a feasible approach, as in many cases the limitation of the solvent has been already reached. Therefore, more reactive P-sources will have to be applied, in analogy to reactions used for the synthesis of monometallic phosphides. An advantage of this approach would be the possibility to control the ratio between the metals and phosphorus in a more precise manner, possibly leading to better independent control of the size, shape, and composition. For catalytic applications, it would be particularly interesting to synthesise facetted particles terminated by well-defined surfaces. Also, their structural characterisation, especially related to surface reconstruction phenomena and the influence of the exposure to air will have to be studied in much more detail.

\section{References}

[1] O. Tegus, E. Brück, K. H. J. Buschow, and F. R. de Boer, Nature 415, 150 (2002).

[2] H. H. Li, C. Jia, X. Meng, and H. H. Li, Front. Chem. 6, 1 (2019).

[3] Y. Shi and B. Zhang, Chem. Soc. Rev. 45, 1529 (2016).

[4] S. Carenco, D. Portehault, C. Boissière, N. Mézailles, and C. Sanchez, Chem. Rev. 113, 7981 (2013).
[5] J. M. Cameron, R. W. Hughes, Y. Zhao, and D. H. Gregory, Chem. Soc. Rev. 40, 4099 (2011).

[6] J. F. Callejas, C. G. Read, C. W. Roske, N. S. Lewis, and R. E. Schaak, Chem. Mater. 28, 6017 (2016).

[7] W. Liu, H. Zhi, and X. Yu, Energy Storage Mater. 16, 290 (2019).

[8] M. Walter, M. I. Bodnarchuk, K. V. Kravchyk, and M. V. Kovalenko, Chim. Int. J. Chem. 69, 724 (2015).

[9] M. E. Bussell, React. Chem. Eng. 2, 628 (2017).

[10] P. E. R. Blanchard, A. P. Grosvenor, R. G. Cavell, and A. Mar, Chem. Mater. 20, 7081 (2008).

[11] E. Muthuswamy, P. R. Kharel, G. Lawes, and S. L. Brock, ACS Nano 3, 2383 (2009).

[12] S. Carenco, D. Portehault, C. Boissière, N. Mézailles, and C. Sanchez, Adv. Mater. 26, 371 (2014).

[13] S. L. Brock and K. Senevirathne, J. Solid State Chem. 181, 1552 (2008).

[14] Y. Lu, T. Wang, X. Li, G. Zhang, H. Xue, and H. Pang, RSC Adv. 6, 87188 (2016).

[15] H. Zhao and Z. Y. Yuan, Catal. Sci. Technol. 7, 330 (2017).

[16] Y. Pei, W. Smith, Y. Cheng, P. Dong, M. Ye, et al., J. Mater. Chem. A 6, 23220 (2018).

[17] C. Xuan, J. Wang, W. Xia, Z. Peng, Z. Wu, et al., ACS Appl. Mater. Interfaces 9, 26134 (2017).

[18] S. Carenco, Z. Liu, and M. Salmeron, ChemCatChem 9, 2318 (2017).

[19] J. Kolny-Olesiak and H. Weller, ACS Appl. Mater. Interfaces 5, 12221 (2013).

[20] D. Ruchira Liyanage, D. Li, Q. B. Cheek, H. Baydoun, and S. L. Brock, J. Mater. Chem. A 5, 17609 (2017).

[21] S. I. Mutinda, D. Li, J. Kay, and S. L. Brock, J. Mater. Chem. A 6, 12142 (2018).

[22] E. Ye, S. Y. Zhang, S. H. Lim, M. Bosman, Z. Zhang, et al., Chem. - A Eur. J. 17, 5982 (2011).

[23] A. C. Colson and K. H. Whitmire, Chem. Mater. 23, 3731 (2011).

[24] G. Lawes, T. Seda, S. L. Brock, B. Kulikowski, D. Li, et al., Chem. Mater. 28, 3920 (2016).

[25] Q. Liang, K. Huang, X. Wu, X. Wang, W. Ma, et al., RSC Adv. 7, 7906 (2017).

[26] A. Hitihami-Mudiyanselage, M. P. Arachchige, T. Seda, G. Lawes, and S. L. Brock, Chem. Mater. 27, 6592 (2015).

[27] M. Bajdich, M. García-Mota, A. Vojvodic, J. K. Nørskov, and A. T. Bell, J. Am. Chem. Soc. 135, 13521 (2013).

[28] D. R. Liyanage, S. J. Danforth, Y. Liu, M. E. Bussell, and S. L. Brock, Chem. Mater. 27, 4349 (2015).

[29] E. Muthuswamy, G. H. L. Savithra, and S. L. Brock, ACS Nano 5, 2402 (2011).

[30] A. Mendoza-Garcia, H. Zhu, Y. Yu, Q. Li, L. Zhou, et al., Angew. Chemie - Int. Ed. 54, 9642 (2015).

[31] J. Liu, Z. Wang, J. David, J. Llorca, J. Li, et al., J. Mater. Chem. A 6, 11453 (2018).

[32] C. C. Hou, Q. Li, C. J. Wang, C. Y. Peng, Q. Q. Chen, et al., Energy Environ. Sci. 10, 1770 (2017).

[33] K. Y. Yoon, Y. Jang, J. Park, Y. Hwang, B. Koo, et al., J. Solid State Chem. 181, 1609 (2008).

[34] A. Lu, Y. Chen, H. Li, A. Dowd, M. B. Cortie, et al., Int. J. Hydrogen Energy 39, 18919 (2014).

[35] K. E. Marusak, A. C. Johnston-Peck, W. C. Wu, B. D. Anderson, and J. B. Tracy, Chem. Mater. 29, 2739 (2017).

[36] J. Kibsgaard, C. Tsai, K. Chan, J. D. Benck, J. K. Nørskov, et al., Energy Environ. Sci. 8, 3022 (2015). 
[37] R. Fruchart, A. Roger, and J. P. Senateur, J. Appl. Phys. 40, 1250 (1969).

[38] L. Ding, Y. Shu, A. Wang, M. Zheng, L. Li, et al., Appl. Catal. A Gen. 385, 232 (2010).

[39] A. W. Burns, A. F. Gaudette, and M. E. Bussell, J. Catal. 260, 262 (2008).

[40] L. Cui, W. Yang, Y. Zheng, J. Liu, Z. Liu, et al., J. Mater. Chem. A 5, 22913 (2017).

[41] D. H. Ha, L. M. Moreau, C. R. Bealing, H. Zhang, R. G. Hennig, et al., J. Mater. Chem. 21, 11498 (2011).
[42] A. F. Gaudette, A. W. Burns, J. R. Hayes, M. C. Smith, R. H. Bowker, et al., J. Catal. 272, 18 (2010).

[43] M. Balli, D. Fruchart, D. Gignoux, J. Tobola, E. K. Hlil, et al., J. Magn. Magn. Mater. 316, 358 (2007).

[44] D. Li, H. Baydoun, C. N. Verani, and S. L. Brock, J. Am. Chem. Soc. 138, 4006 (2016).

[45] H. Nishihara, T. Yoshida, T. Matsukawa, T. Kanomata, G. Strijkers, et al., J. Alloys Compd. 317-318, 258 (2001).

[46] S. Ohta and H. Onmayashiki, Phys. B Condens. Matter 253, 193 (1998). 